\title{
Weak seasonality and synchrony among bacterial communities in small pools
}

\author{
Örjan Östman ${ }^{1, *}$, Silke Langenheder ${ }^{2}$ \\ ${ }^{1}$ Department of Ecology and Genetics/Animal Ecology, and ${ }^{2}$ Department of Ecology and Genetics/Limnology, \\ Uppsala University, Norbyvägen 18D, Uppsala 752 36, Sweden
}

\begin{abstract}
Temporal dynamics of microbial communities show seasonal trends and synchronous dynamics between communities in different aquatic habitats, but previous studies have mainly focused on larger systems such as oceans, rivers, or lakes. However, a large part of aquatic water bodies consists of small pools, ponds, and streams, which tend to be environmentally heterogeneous over relatively small spatial scales. We studied a bacterial metacommunity of 16 rock pools at a spatial scale of $600 \mathrm{~m}^{2}$, which was sampled at approximately monthly intervals over the course of $1 \mathrm{yr}$. We show that temporal dynamics were not evidently synchronous between rock pools over time and that there was no clear seasonal pattern. The environmental variable that explained the most of the temporal dynamics in rock pools over time was water colour, which is often not the main variable explaining spatial differences in bacterial composition between pools. Our results suggest that temporal dynamics of bacterial communities both among and within small water bodies show markedly different patterns compared to larger previously investigated systems, presumably due to their larger heterogeneity and less synchronous environmental changes.
\end{abstract}

KEY WORDS: Bacterioplankton - Seasonal dynamics · Spatial synchrony $\cdot$ Time series $\cdot$ t-RFLP

\section{INTRODUCTION}

Several studies have shown that there are seasonal trends in the composition of aquatic bacterial communities in relation to large-scale phenomena like day length (Gilbert et al. 2012), phytoplankton abundance (e.g. Zwisler et al. 2003, Newton et al. 2006, Rösel et al. 2012), temperature, and water mixing (e.g. Crump \& Hobbie 2005, Allgaier \& Grossart 2006, Shade et al. 2007, Beier et al. 2012, Eiler et al. 2012). This suggests that large-scale external forces are important drivers of temporal changes in bacterial community dynamics, whereas internal processes may be of subordinate importance. Accordingly, several studies have shown that bacterial communities tend to display a high degree of temporal synchrony between sites (Crump \& Hobbie 2005, Kent et al. 2007, Crump et al. 2009). These studies were, however, implemented in relatively large systems, such as major rivers (Crump \& Hobbie 2005, Crump et al. 2009) or lakes (Kent et al. 2007).

A large part of the world's freshwater occurs in relatively small lakes or ponds (Downing et al. 2006), which exhibit comparably greater heterogeneity across sites on relatively small scales than larger lakes due to immediate landscape properties (e.g. Declerck et al. 2006). Moreover, larger lakes and rivers contain larger quantities of waters that buffer shortterm environmental variation, whereas in smaller water bodies, temperature and nutrient concentrations may fluctuate more rapidly, and inflows of bacteria and organic matter from surrounding terrestrial environments may be relatively large, eroding seasonal trends and making small-scale differences more evident. Thus, it is currently unclear whether the consequence of large-scale temporal variation, e.g. seasonality, is similar in small compared to large water bodies or whether intrinsic differences in 
bacterial community composition (BCC) and/or smallscale environmental variation cause communityspecific responses and non-synchronous dynamics. One recent study implemented within streams suggests that small, variable, and disturbance-prone systems lack clear patterns of seasonal changes in BCC (Portillo et al. 2012), but to what extent this may be a general trend that can be extended to small, standing water bodies is currently not known.

We studied the temporal dynamics of BCC in 16 rock pools in a $600 \mathrm{~m}^{2}$ area of the Swedish East coast (Langenheder et al. 2012) on 8 occasions over $1 \mathrm{yr}$, starting in June 2008 and ending in June 2009. Rock pools are small bodies of water that accumulate in rocky outcrops and can vary in volume from a few litres to several cubic metres. Due to their small size, water retention time may be relatively short, and abiotic conditions change rapidly over time, primarily caused by fluctuations in temperature and precipitation that can either dilute nutrient concentrations or increase them due to increasing run-off from the terrestrial environment. Precipitation will result in a decrease of salinity, which will, on the contrary, increase due to wave splashes from the adjacent Baltic Sea. The biotic conditions can also change relatively rapidly, especially due to zooplankton dynamics, which are known to peak 2 to 3 times per growing season in the sampling area (Bengtsson 1993). Rock pools show large environmental heterogeneity between each other, from saline clear water pools close to the sea to humic freshwaters further inland, resulting in clear differences in BCC among pools (Langenheder \& Ragnarsson 2007, Langenheder et al. 2012). Due to the small scale of the sampling area, the climate (temperature, precipitation, and sun radiation) is similar for all studied rock pools. The present study aimed to deduce whether there are evident synchrony and seasonal trends in BCC among these heterogeneous small water bodies and whether the same parameters that drive spatial differences in BCC also drive temporal dynamics.

\section{MATERIALS AND METHODS}

Detailed descriptions of the area, sampling, and processing of samples are given by Langenheder et al. (2012). In short, the sampling site was located on the island of Gräsö at the Baltic Sea Coast in Uppland, Sweden $\left(60^{\circ} 13^{\prime} \mathrm{N}, 18^{\circ} 13^{\prime} \mathrm{E}\right)$. Rock pools were 0.2 to $1.35 \mathrm{~m}$ above sea level 1 to $20 \mathrm{~m}$ from the shoreline in an open rock landscape (see Fig. 1 in Langenheder et al. 2012). There is no tide in the
Baltic Sea, but pools closer to the shore are more likely to be affected by the sea due to frequent wave splashes. Generally, the rock pools are isolated from each other, i.e. there is no water flow between them unless precipitation is very high. Between June 2008 and June 2009, 16 rock pools were sampled on 15 occasions (Langenheder et al. 2012); of these, we included only 8 selected time points because we aimed to have regular time intervals, i.e. approximately monthly, for all 16 rock pools, which is a requirement of the time series models that we used for data analyses (see below). The other time points were excluded to avoid the inclusion of short, infrequent sampling intervals ( $<10 \mathrm{~d})$ and occasions on which some pools had dried out. Sampling was also halted from December 2008 to March 2009 when the pools were frozen solid. Based on data available from all sampling occasions, we classified 8 of the pools (Pools 1 to 8) as permanent because they were never observed to dry out, whereas Pools 9 to 16 were observed to dry out at least once and were thereby classified as temporary.

On each sampling occasion, we measured depth, salinity, abundance of Daphnia, total phosphorus concentration, chlorophyll a concentration, and water colour (absorbance at $436 \mathrm{~nm}$ ), which are known to differ strongly among pools and to influence the composition of bacterial communities (Langenheder \& Ragnarsson 2007, Langenheder et al. 2012). BCC was assessed using terminal restriction fragment length polymorphism (t-RFLP) analysis of the 16S rRNA gene (Langenheder \& Ragnarsson 2007, Langenheder et al. 2012). Peaks that were not detected in both replicates of a sample were deleted, and data were normalised for differences in total signal intensity between different samples by including only peaks that accounted for $>0.5 \%$ of total signal intensity.

To study whether BCC differed among sampling occasions and rock pools, we implemented a permutational analysis of variance (PERMANOVA) based on Bray-Curtis similarity using the 'adonis' function in the 'vegan' package for $\mathrm{R}$ (Oksanen 2011). We used non-metric multi-dimensional scaling (nMDS) to check for seasonal trends in BCC in all rock pools over the study period using the 'isoMDS' function (Oksanen 2011). We calculated pair-wise Pearson correlation coefficients (cross-correlations between rock pools) based on the scores from the first nMDS axis to study whether temporal changes in BCC were synchronous among rock pools. Similar analyses were implemented to study the synchrony of environmental variables. Since r-values $>0.7$ are required to yield p-values $<0.05$ when correlations are 
calculated based on 8 observations, we compared instead the distributions of the observed correlation coefficients with that of a random set of 1000 correlations to test whether some variables were more strongly correlated with each other compared to a random distribution.

To study temporal changes in $\mathrm{BCC}$, we first implemented a principal component analysis (PCA) of the sample (rock pool $\times$ time) $\times$ operational taxonomic unit (OTU) matrix and used the changes in the scores from the first PC axis over time as our estimator of temporal changes in BCC in a rock pool. As we used the same unit for all OTUs (relative abundances), variables were not scaled to unit variances in the PCA to avoid inflated importance of OTU of low abundance in the PCA. PC scores from a PCA represent linear combinations of the sample $\times$ OTU matrix, so temporal changes along the first PC axis represent the main linear temporal changes in $\mathrm{BCC}$ over time.

To analyse whether there were seasonal trends in changes in BCC, we used time series analyses, more specifically partial autocorrelation functions (PACF, e.g. Berryman 1992), which describe the correlation between the residuals of a variable (here, the PC score at time point $t$ ) and a lag $k$ that is not expected due to a propagation of correlations at previous lags (i.e. here, the PC scores at time point $t-1$, i.e. the directly preceding point). PACF values significantly larger than zero indicate that residuals from the average PC score at times $t$ and $t-k$ are correlated and that temporal changes in BCC show seasonal trends. PACF values that are not significantly different from zero indicate that the residuals from the average PC score at times $t$ and $t-k$ are not correlated, indicating no seasonal trends in BCC. Finally, significantly negative PACF values indicate negative correlations of BCC between sampling occasions. We calculated PACFs for the residuals from a linear model with the PC scores as the dependent variable and only intercept as an explanatory variable, i.e. deviations from the average PC score in a rock pool. In the analyses of all pools together, we used a mixed model with pool as a random factor, and in the analysis of each pool separately, we used ordinary least-squares regressions.

We further studied how the BCC at a given time point is influenced by both $\mathrm{BCC}$ and past environmental conditions, i.e. previous time points, using autoregressive moving average (ARMA) models implemented in R 2.13 (see Ripley 2002). That is, the dependent variable, i.e. the PC score at time $t_{\text {, }}$ is modelled as a function of PC scores at time $t-1$ (i.e. $\sim 1$ mo before in our case) to time $t-p$ (i.e. approxi- mately $p$ mo before) and the deviation of environmental variables from the mean from time $t-1$ to time $t-q$. The auto-regressive (AR) lag-structure and moving average (MA) of the full model that included all environmental variables was selected based on the corrected Akaike information criterion (AICc) value of a maximum likelihood (ML) estimate for autoregressive parameters of $p \leq 2$ time lags and a MA $q \leq p$. The PC scores were fitted to a linear mixed effect model (function 'lme' in the nlme package in $\mathrm{R}$ 2.13) with rock pool as a random factor. Environmental data and a dummy variable to code whether a pool was permanent or temporary were used as explanatory variables. Explanatory variables were removed until the AICc value could not be improved, removing the variable that reduced AICc values most at each step. We also implemented ARMA models to study changes in BCC separately for each rock pool, and in this case, the PC scores were calculated from the time $\times$ OTU matrix for each rock pool.

\section{RESULTS}

Both sampling occasion and rock pool accounted for $\sim 20 \%$ each of the variation in community composition in the whole data (PERMANOVA: Occasion $F_{7,102}=4.9, \mathrm{p}<0.001 ;$ Pool $F_{15,102}=4.9, \mathrm{p}<0.001, \mathrm{r}^{2}=$ 0.20 for both). There were no strong seasonal trends in community composition; however, late spring/ summer samples were scattered, whereas autumn and early spring samples were more similar and largely overlapped (Fig. 1). Temporal dynamics of bacterial communities were also generally not synchronous over time, and pair-wise correlation coefficients of nMDS scores between rock pools were on average 0.18 ( $\mathrm{SD}=0.03$, Fig. 2). Except for absorbance and Daphnia abundance, environmental variables showed no more synchronous dynamics among rock pools than expected by chance (Fig. 2).

There were no evident seasonal trends in BCC emerging from the time series analysis. The autocorrelation between the scores of the first PC axis (accounting for $34 \%$ of the total variation in BCC among all samples) at times $t$ and $t-1$, i.e. in our case $\sim 1$ mo earlier, across all rock pools was -0.09 ( $p>$ $0.05)$. None of the larger time lags showed any significant partial autocorrelation (PACF $<0.05$ ). This lack of positive autocorrelation of $\mathrm{BCC}$ over time was also reflected by the ARMA model, in which the AR term for the first $\mathrm{PC}$ axis of the shortest investigated time interval $(A R(1))$ was -0.21 . Higher-order AR terms or MA did not improve the fit of the model. Variation along 
the first PC axis was mainly associated with variation in absorbance $(\triangle \mathrm{AICC}=-3.2, t=2.2)$. No other variable was included in the final model. There were also no evident seasonal trends in $\mathrm{BCC}$ when the time

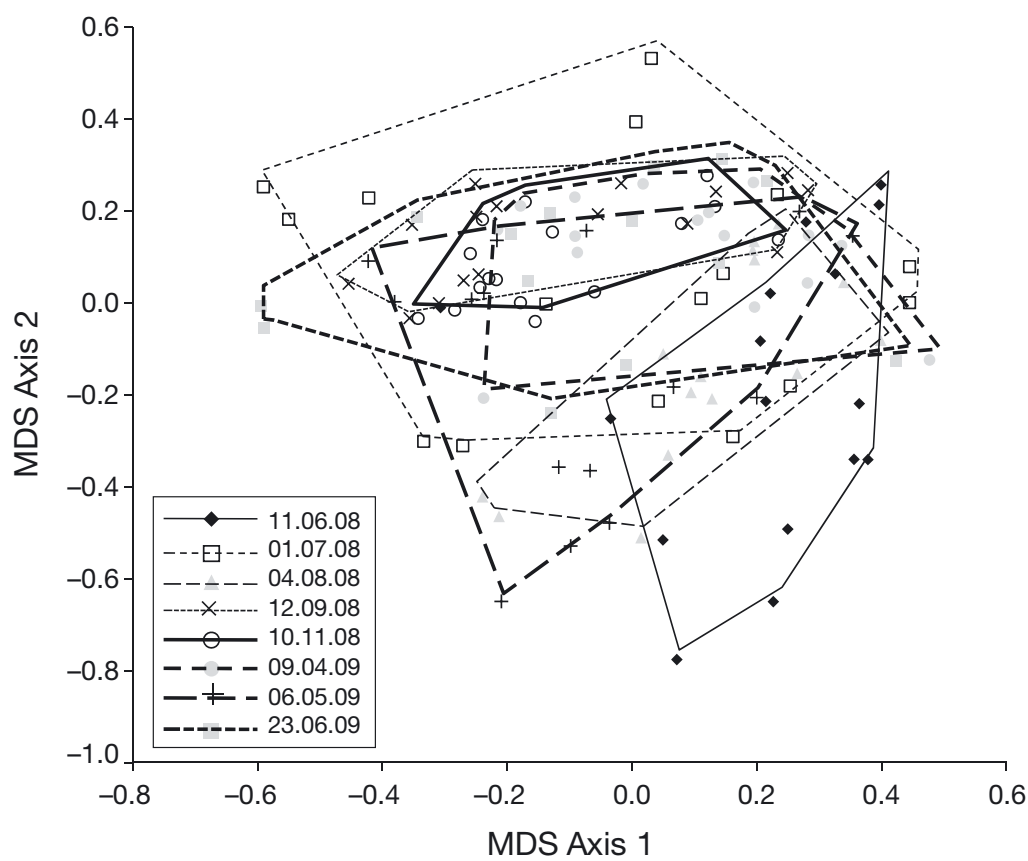

Fig. 1. Results from a non-metric multi-dimensional scaling (nMDS) analysis showing differences in bacterial community composition in all 16 rock pools on all sampling occasions (dates given as d.mo.yr)

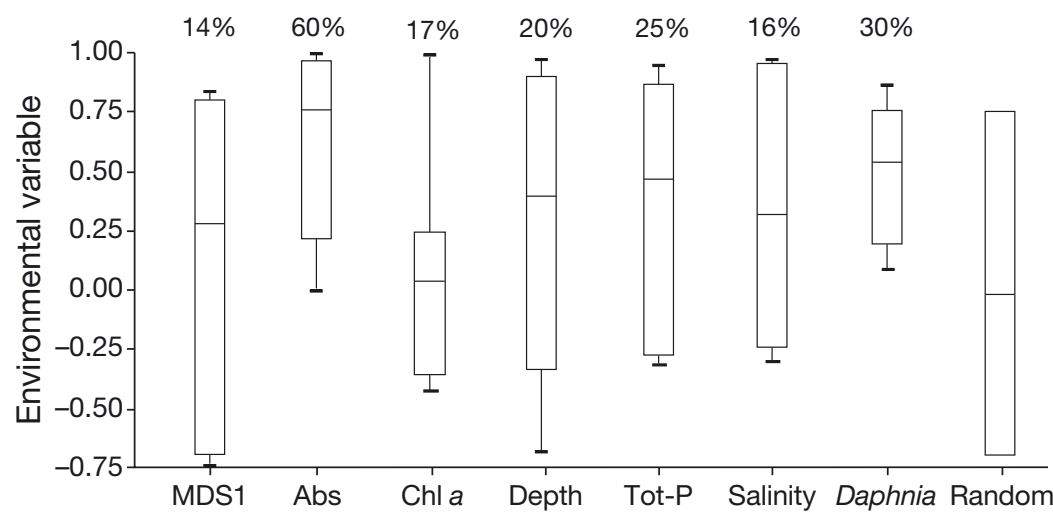

Fig. 2. Correlation coefficients (r) from pair-wise comparisons of nMDS scores and environmental variables between rock pools across sampling occasions. Boxes show the $95 \%$ percentiles, whiskers show minimum and maximum correlation coefficients (no whiskers are shown for the random distribution), and bars are medians. In total, 120 correlations were included, except for Daphnia, for which only 10 comparisons were possible because Daphnia was completely absent in many rock pools. The random distribution was generated from 1000 random correlations of 8 observations. The percentage is the proportion of observed correlations that were larger than the $95 \%$ percentile of the random distribution and thereby indicate that changes in bacterial community composition (BCC) or an environmental factor were more synchronous over time than expected by chance. MDS1: first axis from a non-metric multidimensional scaling of the BCC across all rock pools and sampling occassions; Abs: absorbance at $436 \mathrm{~nm}$; Chl a: chlorophyll a concentration; Tot-P: total phosphorous concentration series analysis was done for each pool separately (Table 1). In fact, PACF and AR(1) tended to be negative (Table 1), confirming the trend that was also apparent from the model including all pools at the same time. The average depth of a rock pool, a proxy for iwater retention time, was not evidently associated with either PACF $(r=0.004, p=0.9)$ or AR(1) $(r=$ $0.19, \mathrm{p}=0.5$ ). Variation in absorbance and salinity were the environmental variables most often associated with the pool-specific PC scores (Table 1).

\section{DISCUSSION}

In contrast to previous studies from larger aquatic ecosystems (e.g. Crump \& Hobbie 2005, Kent et al. 2007, Crump et al. 2009), rock pool bacterial communities generally showed a low degree of synchronous dynamics over time, and that was also the case for most of the measured environmental variables. Thus, despite the short spatial distances between the studied rock pools, there were only weak synchronous changes, suggesting that the temporal dynamics in the composition of bacterial communities were to a larger extent driven by local poolspecific factors, or neutral dynamics, than by changes at larger spatial scales. Previous studies (e.g. Kent et al. 2007, Crump et al. 2009) that observed synchronous dynamics of bacterial communities were conducted in systems that were relatively homogenous, i.e. environmentally similar. Hence, the weaker synchrony in the present study could reflect the high environmental heterogeneity in the rock pool landscape, where conditions within pools change independently from each other. For example, precipitation can dilute salinity and nutrients in pools located close to the shoreline, but it may cause an inflow of terrestrial bacteria, nutrients, and organic carbon in rock pools more distant from the sea. Such site-specific environmental changes may be typical for small water bodies as their characteristics often 
Table 1. Summary of results of time series analyses carried out separately for 16 rock pools. $t$-values illustrate the impact of standardised environmental parameters on the PC scores of the first principal component of a PCA investigating changes in bacterial community composition over time. The environmental variables that were most strongly associated with the PC scores are identified in brackets. PACF(1) is the partial autocorrelation function for a time lag of 1 , i.e. the shortest interval (1 mo) among sampling occasions. $\mathrm{AR}(1)$ is the autoregression term, and MA(1) is the moving average for the same time interval. Longer lags were never included in the models. Abs: absorbance at $436 \mathrm{~nm}$; Chl a: chlorophyll a concentration; Tot-P: total phosphorus concentration; NI: the variable was not included in the final model; NV: no environmental variable was included in the final model

\begin{tabular}{|c|c|c|c|c|}
\hline Pool & $t$-value & $\mathrm{PACF}(1)$ & $\operatorname{AR}(1)$ & $\mathrm{MA}(1)$ \\
\hline P1 & 2.6 (Daphnia) & -0.1 & NI & NI \\
\hline P2 & 2.1 (Daphnia) & -0.45 & -0.63 & NI \\
\hline P3 & $\begin{array}{l}2.6(\text { Abs) } \\
3.5(\text { Chl a) } \\
2.1 \text { (Tot-P) }\end{array}$ & -0.45 & -0.93 & NI \\
\hline $\mathrm{P} 4$ & $\begin{array}{c}4.0 \text { (Abs) } \\
4.0 \text { (Chl a) } \\
6.4 \text { (Salinity) }\end{array}$ & 0.61 & 0.55 & NI \\
\hline P5 & 1.8 (Salinity) & -0.28 & NI & NI \\
\hline P6 & $\begin{array}{c}6.5 \text { (Abs) } \\
5.9 \text { (Salinity) } \\
4.1 \text { (Tot-P) }\end{array}$ & 0.18 & -0.85 & -0.9 \\
\hline P7 & 1.6 (Salinity) & 0.33 & NI & NI \\
\hline P8 & $\begin{array}{c}1.7 \text { (Abs) } \\
2.7 \text { (Depth) }\end{array}$ & -0.47 & -0.55 & NI \\
\hline P9 & $\begin{array}{l}4.3 \text { (Chl a) } \\
7.2 \text { (Tot-P) }\end{array}$ & 0.1 & NI & NI \\
\hline P10 & 1.7 (Salinity) & 0.06 & NI & NI \\
\hline P11 & NV & -0.46 & -0.54 & NI \\
\hline P12 & $1.8(\mathrm{Chl} a)$ & -0.47 & -0.53 & NI \\
\hline P13 & 2.9 (Abs) & 0 & NI & NI \\
\hline P14 & NV & -0.2 & NI & NI \\
\hline P15 & NV & -0.4 & -0.44 & NI \\
\hline P16 & $\begin{array}{c}5.8 \text { (Abs) } \\
4.7 \text { (Salinity) }\end{array}$ & -0.52 & -0.58 & NI \\
\hline
\end{tabular}

depend to a larger extent on the immediate surrounding landscape (Declerck et al. 2006). This heterogeneity seems to erode more synchronous seasonal trends in the composition of the bacterial metacommunity in smaller water bodies.

Although there were no clear seasonal trends in BCC among rock pools, BCC converged during autumn and early in spring after ice break, i.e. during periods of colder water. Even though the BCC at these sampling points was not distinctly different compared to the rest, the pools were more similar to each other on these occasions. One reason for this could be that rock pools became environmentally more similar during autumn and early spring (Langenheder et al. 2012) or, alternatively, that lower temperatures prevent some taxa from growing, thereby dampening random effects in community dynamics in response to changes in the environment, resulting in an increasing homogeneity among pools. In summary, our results suggest that the high environmental heterogeneity among rock pools, which to a large extent is non-synchronous, or local neutral dynamics result in no clear and synchronised seasonal trends in BCC of smaller water bodies.

Also, within rock pools, there were few evident seasonal trends in BCC, i.e. seasonal trends or environmental shifts did not explain a major part of variation in $\mathrm{BCC}$, and there was no autocorrelation in $\mathrm{BCC}$ between sampling points. If anything, $\mathrm{BCC}$ was negatively autocorrelated over time, which may indicate some negative interactions, e.g. antagonistic or negative density-dependent interactions. The lack of clear seasonal patterns stands in strong contrast to studies that have shown clear seasonal changes in BCC in other types of aquatic ecosystems, such as lakes (e.g. Pernthaler et al. 1998, Yannarell et al. 2003, Kent et al. 2007, Rösel et al. 2012), rivers (Crump \& Hobbie 2005, Crump et al. 2009), and oceans (e.g. Murray et al. 1996, Schauer et al. 2003, Gilbert et al. 2012).

It should be noted that a more frequent sampling scheme might have resulted in higher degrees of autocorrelations, and thus, more evident seasonal dynamics cannot be ruled out on a shorter time scale than employed here. However, previous studies (e.g. Kent et al. 2007, Crump et al. 2009) have found that approximately monthly intervals generated seasonal patterns, so the difference in results between our study and previous ones is not evidently due to different sampling frequencies. Moreover, there is a need for future studies that determine temporal community dynamics with methods that have a higher phylogenetic resolution than tRFLP and consider functional traits of bacterial communities. This will also help to reveal whether bacterial communities in rock pools consist of taxa that have a high plasticity and rate of adaptation to fluctuating environmental conditions that may prevent patterns of seasonality and synchrony.

Even though environmental variables were important for temporal dynamics in BCC in our study as well as studies conducted in lakes (e.g. Newton et al. 2006, Kent et al. 2007, Lymer et al. 2008, Eiler et al. 2012), the temporal predictability seems to be lower in rock pools compared to larger systems. Deterministic events, like ice-break, algae blooms, thermal stratification, and mixing, appear to be important drivers of temporal changes in BCC in larger ecosys- 
tems (Shade et al. 2007, Eiler et al. 2012, Gilbert et al. 2012, Rösel et al. 2012), but these are lacking or are non-synchronous in these pools. At least compared to lakes, the water retention time in the rock pools is probably shorter, which could affect temporal changes in BCC (Lindström et al. 2005). Although we found no evidence that the degrees of temporal autocorrelations were related to rock pool depth, our proxy for water retention time, it is still possible that fast water exchange rates may also contribute to the lack of seasonal temporal dynamics. Thus, the high spatial heterogeneity, short water retention time, and lack of sequentially occurring structuring events in many smaller water bodies seem to cause site-specific events or effects that dominate the changes in BCC in these habitats, hence resulting in more unpredictable community dynamics. This is also supported by a study implemented in small streams that showed a high degree of variability in environmental conditions over time and in which no seasonal pattern in BCC could be found (Portillo et al. 2012).

We found that temporal changes in BCC were mainly driven by changes in water colour (a proxy for concentration of humic compounds) and salinity. In a previous study, we found that the spatial variation of the same rock pools was most often associated with differences in salinity and total phosphorus concentrations among pools (Langenheder et al. 2012). Thus, phosphorus and salinity mainly seem to be responsible for the spatial turnover but to a lesser extent drive temporal community dynamics at the local scale, and instead, variation in absorbance seems to be an important driver of temporal turnover. Our results suggest that spatial and temporal dynamics in this rock pool bacterial metacommunity are not primarily driven by the same environmental factors.

Our conclusions that there is a low degree of synchrony among bacterial communities in small heterogeneous water bodies and that there are only weak seasonal trends, in contrast to what has been observed for larger aquatic ecosystems due to a larger heterogeneity and site-specific effects, have implications for forecasting changes in BCC. The abundance of small and temporary water bodies is likely to increase since climate models predict more drastic weather conditions, including heavy precipitation and droughts in many temperate regions. Processes in these small water bodies may thus be important for understanding the temporal variability of future biogeochemical processes. Our results suggest that BCC changes will be more site-specific and less predictable over larger spatial scales under such a scenario.
Acknowledgements. We thank M. Berga, A. Székely, J. Zie, $\mathrm{X}$. Feng, and J. Olofsson for help during the field sampling and in the lab. A. Ives provided invaluable help with the time series analysis. This work was funded by grants from the Swedish Research Council Formas and a Marie Curie reintegration grant to S.L. and the Swedish Research Council Vetenskapsrådet to Ö.Ö.

\section{LITERATURE CITED}

Allgaier M, Grossart HP (2006) Seasonal dynamics and phylogenetic diversity of free-living and particle-associated bacterial communities in four lakes in northeastern Germany. Aquat Microb Ecol 45:115-128

Beier S, Mohit V, Ettema TJG, Östman Ö, Tranvik LJ, Bertilsson S (2012) Pronounced seasonal dynamics of freshwater chitinase genes and chitin processing. Environ Microbiol 14:2467-2479

> Bengtsson J (1993) Interspecific competition and determinants of extinction in experimental populations of three rockpool Daphnia species. Oikos 67:451-464

$>$ Berryman AA (1992) On choosing models for describing and analyzing ecological time series. Ecology 73:694-698

$>$ Crump BC, Hobbie JE (2005) Synchrony and seasonality in bacterioplankton communities of two temperate rivers. Limnol Oceanogr 50:1718-1729

> Crump BC, Peterson BJ, Raymond PA, Amon RMW, Rinehart A, McClelland JW, Holmes RM (2009) Circumpolar synchrony in big river bacterioplankton. Proc Natl Acad Sci USA 106:21208-21212

Declerck S, De Bie T, Ercken D, Hampel H and others (2006) Ecological characteristics of small farmland ponds: associations with land use practices at multiple spatial scales. Biol Conserv 131:523-532

Downing JA, Prairie YT, Cole JJ, Duarte CM and others (2006) The global abundance and size distribution of lakes, ponds, and impoundments. Limnol Oceanogr 51: 2388-2397

> Eiler A, Heinrich F, Bertilsson S (2012) Coherent dynamics and association networks among lake bacterioplankton taxa. ISME J 6:330-342

Gilbert JA, Steele JA, Caporaso JG, Steinbrueck L and others (2012) Defining seasonal marine microbial community dynamics. ISME J 6:298-308

Kent AD, Yannarell AC, Rusak JA, Triplett EW, McMahon KD (2007) Synchrony in aquatic microbial community dynamics. ISME J 1:38-47

Langenheder S, Ragnarsson H (2007) The role of environmental and spatial factors for the composition of aquatic bacterial communities. Ecology 88:2154-2161

- Langenheder S, Berga M, Östman Ö, Szekely AJ (2012) Temporal variation of $\beta$-diversity and assembly mechanisms in a bacterial metacommunity. ISME $\mathrm{J}$ 6: 1107-1114

Lindström ES, Kamst-Van Agterveld MP, Zwart G (2005) Distribution of typical freshwater bacterial groups is associated with $\mathrm{pH}$, temperature, and lake water retention time. Appl Environ Microbiol 71:8201-8206

Lymer D, Logue JB, Brussaard CPD, Baudoux AC, Vrede K, Lindström ES (2008) Temporal variation in freshwater viral and bacterial community composition. Freshw Biol 53:1163-1175

Murray AE, Hollibaugh JT, Orrego C (1996) Phylogenetic compositions of bacterioplankton from two California 
estuaries compared by denaturing gradient gel electrophoresis of 16S rDNA fragments. Appl Environ Microbiol 62:2676-2680

Newton RJ, Kent AD, Triplett EW, McMahon KD (2006) Microbial community dynamics in a humic lake: differential persistence of common freshwater phylotypes. Environ Microbiol 8:956-970

Oksanen J (2011) Multivariate analysis of ecological communities in R: vegan tutorial. Available at http://cc.oulu. fi/ jarioksa/opetus/metodi/vegantutor.pdf (accessed 16 August 2012)

Pernthaler J, Glockner FO, Unterholzner S, Alfreider A, Psenner R, Amann R (1998) Seasonal community and population dynamics of pelagic bacteria and archaea in a high mountain lake. Appl Environ Microbiol 64: 4299-4306

Portillo MC, Anderson SP, Fierer N (2012) Temporal variability in the diversity and composition of stream bacterioplankton communities. Environ Microbiol 14: 2417-2428

Ripley BD (2002) Time series in R 1.5.0. R News 2/2:2-7,

Editorial responsibility: Jed Fuhrman,

Los Angeles, California, USA available at www.r-project.org/doc/Rnews/Rnews_20022.pdf

Rösel S, Allgaier M, Grossart HP (2012) Long-term characterization of free-living and particle-associated bacterial communities in Lake Tiefwaren reveals distinct seasonal patterns. Microb Ecol 64:571-583

Schauer M, Balague V, Pedros-Alio C, Massana R (2003) Seasonal changes in the taxonomic composition of bacterioplankton in a coastal oligotrophic system. Aquat Microb Ecol 31:163-174

Shade A, Kent AD, Jones SE, Newton RJ, Triplett EW, McMahon KD (2007) Interannual dynamics and phenology of bacterial communities in a eutrophic lake. Limnol Oceanogr 52:487-494

Yannarell AC, Kent AD, Lauster GH, Kratz TK, Triplett EW (2003) Temporal patterns in bacterial communities in three temperate lakes of different trophic status. Microb Ecol 46:391-405

Zwisler W, Selje N, Simon M (2003) Seasonal patterns of the bacterioplankton community composition in a large mesotrophic lake. Aquat Microb Ecol 31:211-225

Submitted: January 21, 2013; Accepted: May 29, 2013 Proofs received from author(s): June 19, 2013 